\title{
Behaviour of Reinforced Concrete Beams Bonded with Glass Fibre Reinforced Polymer and Carbon Fibre Reinforced Polymer Sheets
}

\author{
Todupunoori Shiva Sai, G.A.V.S. Sandeep Kumar, N. Kiran Kumar, Cyril Thomas A
}

\begin{abstract}
Concrete, a mixture of different aggregates bonded with cement, first developed around 150BC in Rome has been bedrock to the modern Infrastructure. It is used to build everything from roads, bridges, dams to sky scrapers. Strengthening concrete is traditionally done by using steels but the developments in technology in recent decades allowed to use fiber reinforced plastics which are externally bonded to concrete. Such composite materials offer high strength, low weight, corrosion resistance, high fatigue resistance, easy and rapid installation and minimal change in structural geometry. This study investigates the behavior of reinforced concrete beams bonded with fiber composites. A numerical study is conducted to study the behavior of $R C$ beam under Static third point loading. Concrete beam specimens with dimensions of $150 \mathrm{~mm}$ width, $300 \mathrm{~mm}$ height, and $2600 \mathrm{~mm}$ length are modelled. These beams are externally bonded with Glass Fiber Reinforced Polymer (GFRP) sheets and Carbon Fibre Reinforced Polymer (CFRP) sheets. In present study, we examine the performance of reinforced concrete beams which are bonded with GFRP and CFRP sheets with various thicknesses (1, $2 \& 3 \mathrm{~mm})$ using ABAQUS in terms of failure modes, enhancement of load capacity, load-deflection analysis and flexural behaviour.
\end{abstract}

Key words: CFRP, Flexural Strengthening, GFRP, load vs deflection.

\section{INTRODUCTION}

The conventional material used as a reinforcement to improve the tensile strength of concrete is steel. But it has certain drawbacks such as low corrosive and alkali resistance,high handling costs due to its heavy wieght. So, to counteract these drawbacks alternatives such as fibre reinforced plastics are used which have better fatigue and corrosive properties and also are light in wieght when compared with steel.The technology to use fiber reinforced plastics along with steels is being widely used even though its relatively a new devolopemnt in the field of construction.An overwhelming evidence obtained through research suggests

Revised Manuscript Received on February 05, 2020.

* Correspondence Author

Todupunoori Shiva Sai*, Dept. of Civil Engineering, VNRVJIET, Hyderabad, India. Email: shivasai958@gmail.com

G.A.V.S.Sandeep Kumar, Dept. of Civil Engineering, VNRVJIET, Hyderabad, India. Email: sandeepkumar_gavs@vnrvjiet.in

Dr.N. Kiran Kumar, Dept. of Mechanical Engineering, VNRVJIET, Hyderabad, India. Email: kirankumar_n@vnrvjiet.in

Dr. Cyril Thomas A, Dept. of Civil Engineering, NEC, Kovilpatti, India. Email: cyrilstrer@gmail.com

(C) The Authors. Published by Blue Eyes Intelligence Engineering and Sciences Publication (BEIESP). This is an open access article under the CC BY-NC-ND license (http://creativecommons.org/licenses/by-nc-nd/4.0/) that externally bonded fiber reinforced polymers are increasing the effectiveness of properties of reinforced concrete. The studies conducted using beams which are bonded with FRP's showed a decrease in ductility which is caused due to linear elasticity of FRP material up to tensile rupture. To compensate this issue glass fibre reinforced polymers are used inspite of their lower elastic moduli and tensile strength GFRP's make up in their break resistance and high deformability which makes them good material for strengthening. If both Glass fibre reinforced plastic(GFRP) and carbon fibre reinforced plastic (CFRP) are used as a combination the high ductility and high strength of the respective carbon fibers compensate each other which also improves the fracture strains of the hybrid fiber composite. The ductility of these beams can be improved by changing the thickness of GFRP and CFRP's, and also the tensile strength of hybrid beams is more distributed than when alone Frp's are used.

Flexural Strengthening of Beams:

Flexure strengthening of beams can be obtained by using a variety of ways - external post tensioning method, Near-Surface Mounted (NSM) system and Externally Bonded (EB) system.

Although the use of advanced fiber-reinforced polymer composite (FRP) which are externally bonded has found its way through the other conventional, above mentiond methdods due to thier relatively new technology.Hence a grate deal of research both theoretical and experimental is being conducted.

\section{NUMERICAL STUDY}

Present study carry out the flexure behaviour of Reinforced concrete beams bonded with glass fiber reinforced polymer sheets(GFRP) and carbon fibre reinforced polymer sheets(CFRP) of different thicknesses(Numerical study). In this study finite element (FE) method is employed which is processed through ABAQUS software. A beam with standard size is modelled as solid extrusion member, glass fibre reinforced polymer sheets and carbon fibre reinforced polymer sheets are modelled as 3-D shell elements in Abaqus. The analysis is carried out for Reinforced Concrete beam(control beam), Reinforced Concrete beam bonded with $1 \mathrm{~mm}, 2 \mathrm{~mm}$ and 3mm GFRP sheet and Reinforced Concrete beam bonded with $1 \mathrm{~mm}, 2 \mathrm{~mm}$ and $3 \mathrm{~mm}$ CFRP sheet. The load vs deflection graphs are plotted for above modelled beams to obtain the bonded beam which controlled the maximum deflection when compared with the deflection values retrieved from control beam. 
Behaviour of Reinforced Concrete Beams Bonded with Glass Fibre Reinforced Polymer and Carbon Fibre Reinforced Polymer Sheets

\section{METHODOLOGY}

Methodology deals with the modelling and analysis of a beam in a step by step procedure as follows:

A.Part:

Part is also known as Geometry in Abaqus. It is a basic tool which also acts as a drawing tool. The required part can be drawn in 1-D, 2-D, and 3-D Geometry using nodes, lines, rectangle, circle etc.. The parts modelled in this project are concrete beams named as 3 Dimensional solid continuum element (C3D8R) with 8 nodes, steel bars as 3 Dimensional truss element (T3D2) with 2 nodes, GFRP and CFRP sheets as 3 Dimensional shell elements (S8R) which is an doubly curved thick shell with 8 number of nodes.

\section{B.Material Properties:}

The part which is developed in above step i.e in 3.A has no identity. It is the foremost important tool in ABAQUS to recognise the particular type of material by the software one has to assign the each and every property of that material from material library in ABAQUS which allows us to assign different material properties to different parts of the model-as per our requirement. Materials available in Abaqus vary from concrete, steel, metals, plastics, rubber to rocks and granular soils. To carry out the project work concrete is modelled using following material properties such as density, elastic properties and also concrete smeared cracking pattern from plasticity properties which uses stress-strain curve of concrete as input and also we consider tension stiffening as one of the input. Stress-strain curves for different grade of concrete is shown below:

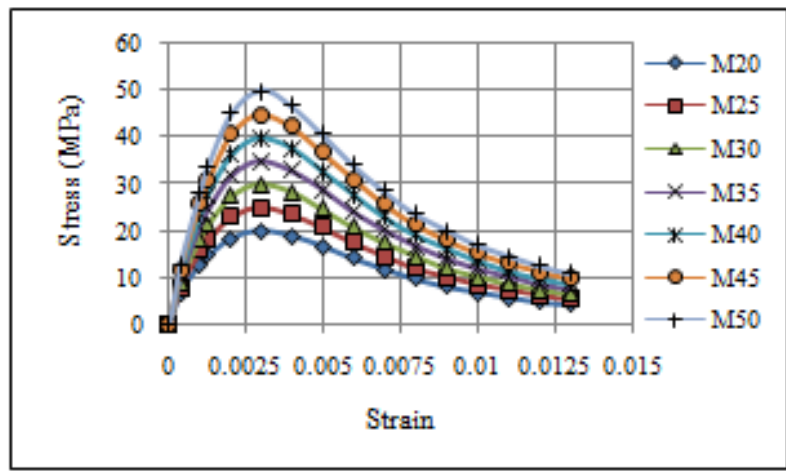

Fig. 1. Stress-strain curves for different grades of concrete To carry out project work M-50 grade of concrete is considered. The strain value at which stress value reduced to zero i.e., $\varepsilon^{*}=0.003$. poisson ratio of concrete used is 0.15 .

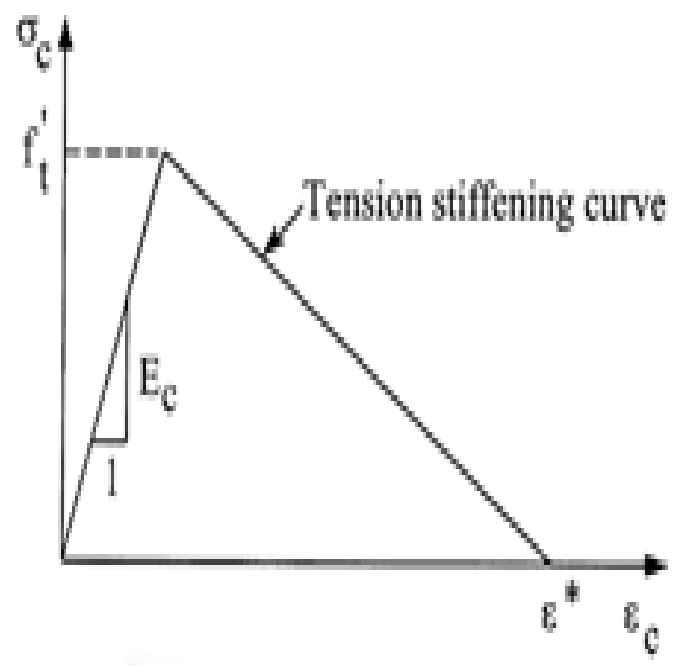

Fig. 2 . Tension stiffening model for reinforced concrete Glass Fibre Reinforced Polymer (GFRP) and Carbon Fibre Reinforced Polymer (CFRP)

The properties of both the composites used in this study are mentioned in below table.

Table.1 Properties of GFRP \& CFRP

\begin{tabular}{|l|c|c|}
\hline \multicolumn{1}{|c|}{ Property } & GFRP & CFRP \\
\hline $\begin{array}{l}\text { Longitudnal tensile } \\
\text { strength }\end{array}$ & $1500 \mathrm{MPa}$ & $2700 \mathrm{MPa}$ \\
\hline $\begin{array}{l}\text { Transverse tensile } \\
\text { strength }\end{array}$ & $30 \mathrm{MPa}$ & $45 \mathrm{MPa}$ \\
\hline $\begin{array}{l}\text { Longitudnal } \\
\text { compressive strength }\end{array}$ & $1500 \mathrm{MPa}$ & $2700 \mathrm{MPa}$ \\
\hline $\begin{array}{l}\text { Transverse compressive } \\
\text { strength }\end{array}$ & $120 \mathrm{MPa}$ & $200 \mathrm{MPa}$ \\
\hline $\begin{array}{l}\text { Longitudnal shear } \\
\text { strength }\end{array}$ & $55 \mathrm{MPa}$ & $80 \mathrm{MPa}$ \\
\hline $\begin{array}{l}\text { Transverse shear } \\
\text { strength }\end{array}$ & $60000 \mathrm{MPa}$ & $130000 \mathrm{MPa}$ \\
\hline $\begin{array}{l}\text { Elastic modulus in } \mathrm{x} \\
\text { direction, } \mathrm{E}_{11}\end{array}$ & $8000 \mathrm{MPa}$ & $13500 \mathrm{MPa}$ \\
\hline $\begin{array}{l}\text { Elastic modulus in } \mathrm{y} \\
\text { direction, } \mathrm{E}_{22}\end{array}$ & $4000 \mathrm{MPa}$ & $5700 \mathrm{MPa}$ \\
\hline $\begin{array}{l}\text { Shear modulus } \\
\mathrm{G}_{12}=\mathrm{G}_{13}\end{array}$ & $2400 \mathrm{MPa}$ & $3500 \mathrm{MPa}$ \\
\hline Shear modulus, $\mathrm{G}_{23}$ & 0.17 & 0.20 \\
\hline Poisson number, $\mathrm{v}_{12}$ & & \\
\hline
\end{tabular}

\section{C.Assembly:}

As the name suggests, Assembly tool is used to combine different parts. In this Instance command is used to align different coordinate systems of their respective parts into one single global coordinate system there by creating an assembly.Instance command is mainly used to develop the material along with the assigned material properties.

D. Step:

Step is a tool to perform static analysis in Abaqus/Standard for a load change of different magnitudes. Basically this involves in a time period analysis. Step tool is especially useful for complex loading of a model, which involves applying varied magnitudes of loads for different parts of the model or load applied at a particular place which may vary with time. Such processes are divided into steps with a specified time interval. Accurate results can be obtained by increasing the number of steps.

\section{E.Interaction:}

Interaction tool is used to define the kind of contact between parts in an assembly. Since abaqus does not recognize the surface contact between different parts generated in the assembly module it is necessary to specify the kind of bond present between different parts like an adhesive agent thereby generating a single uniform material.

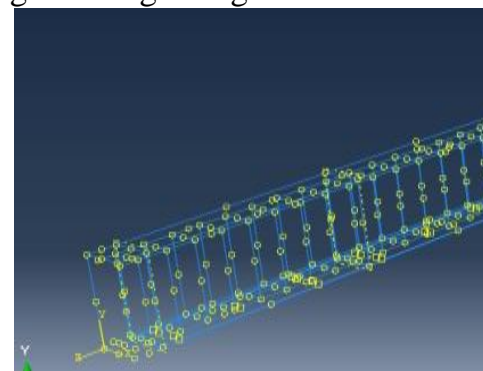

Fig.3. Interaction between concrete and steel 


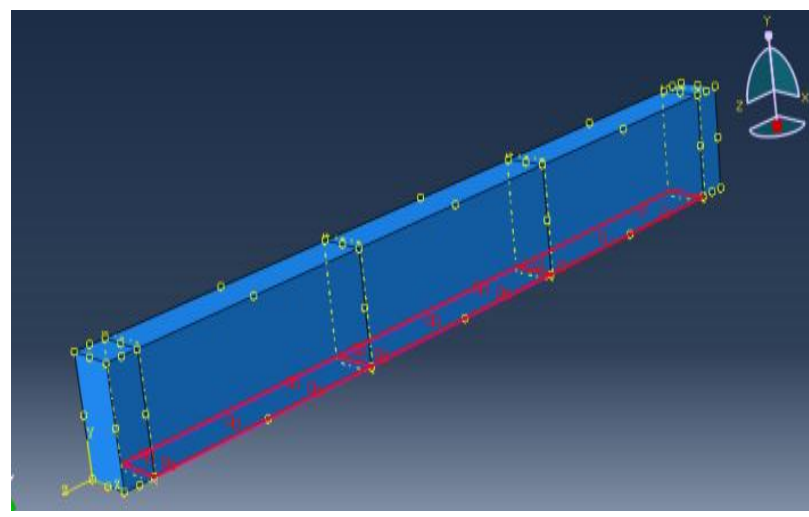

Fig.4. Interaction between Concrete and GFRP/CFRP F. Mesh:

Abaqus utilises finite element method to solve problems using geometry of the model. The entire model is divided into small number of elements, which are connected to one other through nodes. The generated mesh is a combination of elements and nodes. As mesh density increases we can obtain more accurate results but it also increases the analysis time.

\section{Boundary Conditions \& Loads:}

It is one of the basic and most important tool in any software. Based on type of analysis, boundary conditions which are used to restrain the model from moving or to definitively move it in a particular direction can be assigned from the Abaqus library. Different kinds and magnitudes of loads are assigned to the module through this process. It is easy relatively for carrying out analysis for different types of loads with different magnitudes and different boundary conditions in Abaqus.

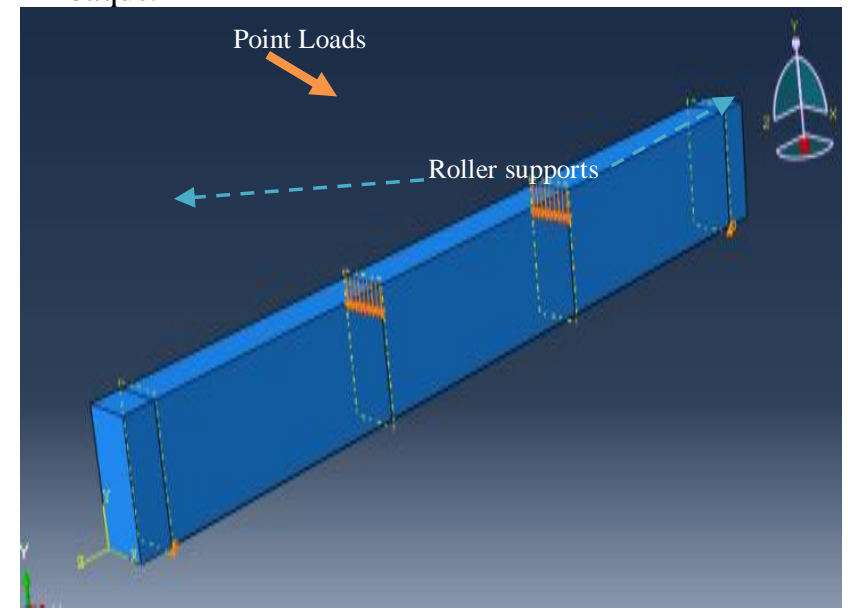

Fig.5. Beam with boundary conditions and loading

\section{G. Job:}

Job is a type of tool used for analysing the whole element which is modelled in above steps i.e.,(3.A to 3.G). The time taken to run and complete the analysis depends on the time period mentioned in step module and also on the mesh density.

\section{H. Visualisation:}

It is the last and final step in Abaqus,Inwhich both results obtained from analysis and numerical study can be seen in different formats. The display can be customised to suit our requirements.

\section{EXPERIMENTAL PROCEDURE}

A totally of 7 beams were modelled and designated as shown in below:
RCC - Reinforced Concrete Beam (Controlled beam).

RCCGF1 - Reinforced Concrete Beam bonded with 1mm thick GFRP element.

RCCGF2 - Reinforced Concrete Beam bonded with 2mm thick GFRP element.

RCCGF3 - Reinforced Concrete Beam bonded with 3mm thick GFRP element.

RCCCF1 - Reinforced Concrete Beam bonded with 1mm thick CFRP element.

RCCCF2 - Reinforced Concrete Beam bonded with 2mm thick CFRP element.

RCCCF3 - Reinforced Concrete Beam bonded with 3mm thick CFRP element.

\section{RESULTS AND DISCUSSIONS}

Comparisons of the deflections in RCC,CFRP and GFRP:

The load-deflection behaviour of all the beams are recorded. And The deflection (Middle) of each beam was compared with that of their respective control beam. The deflection behaviour of the beams are as shown in below Tables.

Table.2. Load vs deflection for RCC, RCCGF1 \& RCCCF1.

\begin{tabular}{|c|c|c|c|c|c|}
\hline \multirow[b]{2}{*}{$\begin{array}{l}\text { Load } \\
(\mathrm{kN})\end{array}$} & \multicolumn{5}{|c|}{ Deflection(mm) } \\
\hline & RCC & RCCGF1 & $\begin{array}{c}\% \\
\text { Decrease } \\
\text { in } \\
\text { deflection } \\
\text { (RCC \& } \\
\text { RCCGF1) } \\
\text { (\%) }\end{array}$ & RCCCF1 & $\begin{array}{c}\% \\
\text { Decrease } \\
\text { in } \\
\text { deflection } \\
\text { (RCC \& } \\
\text { RCCCF1) } \\
(\%)\end{array}$ \\
\hline 5 & 1.112 & 1.059 & 4.745 & 1.051 & 5.485 \\
\hline 10 & 2.224 & 2.116 & 4.868 & 2.107 & 5.243 \\
\hline 15 & 3.344 & 3.198 & 4.354 & 3.132 & 6.342 \\
\hline 20 & 4.852 & 4.577 & 5.675 & 4.491 & 7.435 \\
\hline 25 & 6.465 & 6.132 & 5.148 & 5.840 & 9.675 \\
\hline 30 & 9.858 & 8.424 & 14.547 & 8.138 & 17.450 \\
\hline 35 & 14.199 & 11.707 & 17.548 & 11.339 & 20.144 \\
\hline 40 & 16.906 & 13.955 & 17.453 & 13.282 & 21.436 \\
\hline 45 & 19.211 & 15.888 & 17.297 & 14.935 & 22.258 \\
\hline 50 & 22.886 & 18.973 & 17.098 & 17.739 & 22.490 \\
\hline
\end{tabular}

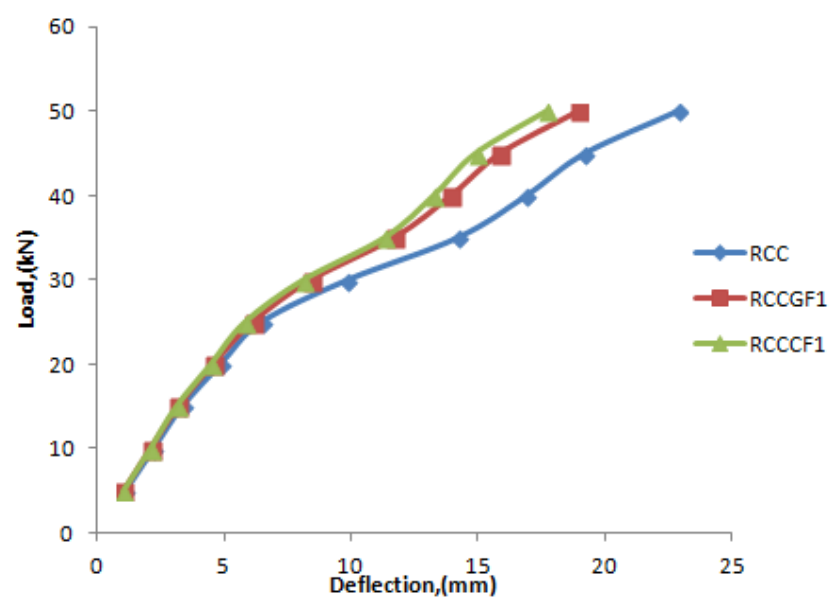

Fig.6. Load vs deflection for RCC, RCCGF1 \& RCCCF1. 
From table. 2 we can conclude that,the deflection for beam with GFRP was controlled from (0-17.09)\% when compared with RCC beam and the deflection for beam with CFRP was controlled from (0-22.49)\% when compared with RCC beam.

Table.3 Load vs deflection for RCC,RCCGF2 \&

RCCCF2.

\begin{tabular}{|c|c|c|c|c|c|}
\hline \multirow[b]{2}{*}{$\begin{array}{l}\text { Load } \\
(\mathrm{kN})\end{array}$} & \multicolumn{5}{|c|}{ Deflection (mm) } \\
\hline & RCC & RCCGF2 & $\begin{array}{l}\% \text { Decrease } \\
\text { in } \\
\text { deflection } \\
\text { (RCC \& } \\
\text { RCCGF2) } \\
(\%)\end{array}$ & RCCCF2 & $\begin{array}{c}\% \\
\text { Decrease } \\
\text { in } \\
\text { deflection } \\
\text { (RCC \& } \\
\text { RCCCF2) } \\
\text { (\%) }\end{array}$ \\
\hline 5 & 1.112 & 1.025 & 7.824 & 1.018 & 8.453 \\
\hline 10 & 2.224 & 2.114 & 4.946 & 2.039 & 8.318 \\
\hline 15 & 3.344 & 3.183 & 4.815 & 3.022 & 9.629 \\
\hline 20 & 4.852 & 4.500 & 7.255 & 4.296 & 11.459 \\
\hline 25 & 6.465 & 5.822 & 9.946 & 5.556 & 14.060 \\
\hline 30 & 9.858 & 7.588 & 23.027 & 7.270 & 26.253 \\
\hline 35 & 14.199 & 10.772 & 24.135 & 9.872 & 30.474 \\
\hline 40 & 16.906 & 12.324 & 27.103 & 11.358 & 32.817 \\
\hline 45 & 19.211 & 13.734 & 28.510 & 12.676 & 34.017 \\
\hline 50 & 22.886 & 16.134 & 29.503 & 14.923 & 34.794 \\
\hline
\end{tabular}

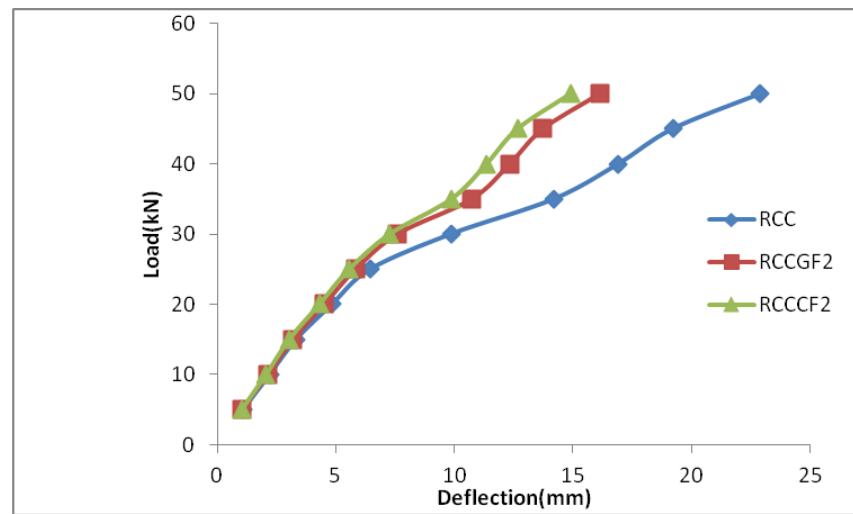

Fig.7. Load vs deflection for RCC,RCCGF2 \& RCCCF2. From table.3. we can conclude that the deflection for RCCGF2 was controlled from (0-29.5)\% when compared with RCC beam and the deflection for RCCCF2 was controlled from (0-34.79)\% when compared with RCC beam.

Table.4. Load vs deflection for RCC,RCCGF3 \&

RCCCF3.

\begin{tabular}{|c|c|c|c|c|c|}
\hline \multirow[b]{2}{*}{$\begin{array}{c}\text { Load } \\
(\mathrm{kN})\end{array}$} & \multicolumn{5}{|c|}{ Deflection (mm) } \\
\hline & RCC & $\begin{array}{c}\text { RCCGF } \\
3 \\
\end{array}$ & $\begin{array}{c}\% \\
\text { Decrease } \\
\text { in } \\
\text { deflection } \\
\text { (RCC \& } \\
\text { RCCGF3 } \\
\text { ) } \\
(\%) \\
\end{array}$ & $\begin{array}{c}\text { RCCCF } \\
3 \\
\end{array}$ & $\begin{array}{c}\% \\
\text { Decrease } \\
\text { in } \\
\text { deflection } \\
\text { (RCC \& } \\
\text { RCCCF3 } \\
\text { ) } \\
(\%) \\
\end{array}$ \\
\hline 5 & 1.112 & 1.015 & 8.723 & 0.988 & 11.151 \\
\hline 10 & 2.224 & 2.044 & 8.094 & 1.978 & 11.061 \\
\hline 15 & 3.344 & 2.988 & 10.646 & 2.926 & 12.500 \\
\hline 20 & 4.852 & 4.316 & 11.047 & 4.131 & 14.860 \\
\hline 25 & 6.465 & 5.643 & 12.715 & 5.317 & 17.757 \\
\hline 30 & 9.858 & 7.478 & 24.143 & 6.697 & 32.065 \\
\hline 35 & 14.199 & 9.414 & 33.700 & 8.911 & 37.242 \\
\hline 40 & 16.906 & 10.767 & 36.313 & 10.108 & 40.211 \\
\hline 45 & 19.211 & 11.622 & 39.503 & 10.769 & 43.944 \\
\hline 50 & 22.886 & 13.383 & 41.523 & 12.178 & 46.788 \\
\hline
\end{tabular}

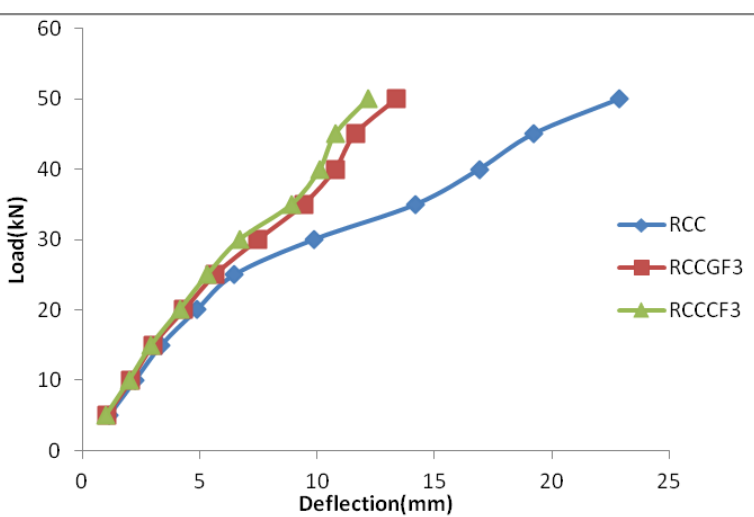

Fig.8. Load vs deflection for RCC, RCCGF3 \& RCCCF3. From table.4. it can be concluded that, the deflection for beam with GFRP was controlled from $(0-41.52) \%$ and the beam with CFRP was controlled from $(0-46.78) \%$ when compared with RCC beam.

\section{CONCLUSIONS}

The following conclusions are derived based on Finite element(FE) analysis.

\section{Comparison of RCC,GFRP \& CFRP beams:}

- The beams with GFRP of greater thickness and beams with CFRP of greater thickness are controlling higher deflections compared to RCC beam.

- $\quad$ The beams bonded with CFRP sheets are showing better results when compared with beam bonded with GFRP.

- The beam bonded with $1 \mathrm{~mm}$ thick GFRP sheet is controlling deflection by $17.09 \%$ and beam bonded with $1 \mathrm{~mm}$ thick GFRP sheet is controlling deflection by $22.49 \%$ when compared with control beam.

- The beam bonded with $2 \mathrm{~mm}$ thick GFRP sheet is controlling deflection by $29.5 \%$ and the beam bonded with $2 \mathrm{~mm}$ thick CFRP sheet is controlling deflection by $34.79 \%$ compared with control beam.

- The beam bonded with $3 \mathrm{~mm}$ thick GFRP sheet is controlling deflection by $41.5 \%$ and the beam bonded with 3mm thick CFRP sheet is controlling deflection by 46.78\% compared with control beam.

- From the results we can conclude that the beams bonded with CFRP sheet is having greater deflection controlling capacity compared with beam bonded with GFRP sheet.

\section{REFERENCES}

1. MoatazBadawi, KhaledSoudki (2002). "The Effect of FRP Wraps on the Tensile Strength of Plain and Reinforced Concrete Beams" , 4th Structural Specialty Conference of the Canadian Society for Civil Engineering, Vol. 42, June 5-8.

2. Tarek H. Almusallam and Yousef A. Al-Salloum (2003).Use of Glass FRP sheets as external flexure reinforcement in RC beams.Department of Civil Engineering, King Saud University.

3. Hsuan-TehHu , Fu-Ming Lin, Yih-Yuan Jan (2004). "Nonlinear finite element analysis of reinforced concrete beams strengthened by fiber-reinforced plastics". Journal of Composite Structures.

4. J.A.O. Barros, A.S. Fortes (2005). Flexural strengthening of concrete beams with CFRP laminates bonded into slits.Cement \& Concrete Composites 27 (2005) 471-480.

5. M.R. Esfahania, M.R. Kianoushb, A.R. Tajaria(2007).Flexural behaviour of reinforced concrete beams strengthened by CFRP sheets.Materials Research, Vol. 8, No. 3, 357-360. 
6. Abaqus/CAE Version 6.11, (2011) User's Manual, AbaqusIncDassaultSystèmes, Simulia Corp., Providence, RI, USA.

7. N. Attari, S. Amziane, M. Chemrouk (2012). Flexural strengthening of concrete beams using CFRP, GFRP and hybrid FRP sheets.Construction and Building Materials 37, 746-757.

8. H.R. Ronagh, A. Eslami (2013). Flexural retrofitting of RC buildings using GFRP/CFRP - A comparative study. Composites: Part B 46, 188-196.

9. Tara Sen, H.N. Jagannatha Reddy (2013). Strengthening of RC beams in flexure using natural jute fibre textile reinforced composite system and its comparative study with CFRP and GFRP strengthening systems.International Journal of Sustainable Built Environment 2, 41-55.

10. Dr. Cyril Thomas.A. "Behaviour of Thin-webbed Castellated Beams Strengthened using CFRP", International Conference on Composite Materials and Structures 2017 (ICCMS 2017).

\section{AUTHORS PROFILE}

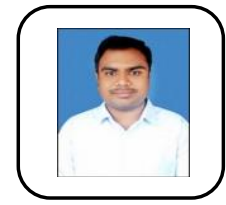

Todupunoori Shiva Sai pursuing master of technology in structural engineering in VNR Vignana Jyothi Institute of Engineering and Technology, Bachupally, Hyderabad, INDIA. Had completed Bachelor of Technology in VNR Vignana Jyothi Institute of Engineering and Technology.

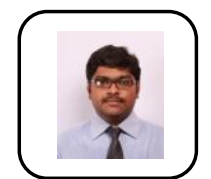

G AVS Sandeep Kumar, working as Assistant Professor in the Department of Civil Engineering in VNRVJIET, Hyderabad, India. Pursuing Ph.D in NIT Tiruchirappalli, has published 4 publications, his research includes sustainable construction material, behaviour of composite materials in concrete construction and concrete for special applications.

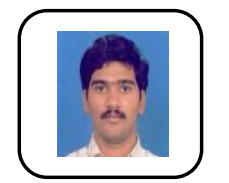

Dr.N.Kiran Kumar, working as Associate Professor in the Department of Mechanical Engineering inVNRVJIET,Hyderabad, India.Obtained his Ph.D on the topic"Impact on composite materials: Experiments and simulation" from IIT Delhi in 2015. His research interests include Thermal Behavior of Composites and Effect of Imperfections on the Properties of Composites.

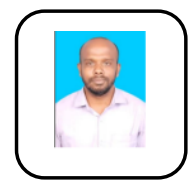

Dr. Cyril Thomas.A, working as Assistant Professor in the Department of Civil Engineering, National Engineering College, K.R.Nagar, Kovilpatti, Tamil Nadu, India. Obtained his Ph.D. on the topic "Behaviour of Thin-webbed Castellated Beams Strengthened using CFRP" from National Institute of Technology, Tiruchirappalli, India. His research interests include Strengthening of Steel Structures, Repair and Rehabilitation of Structures, CFRP Strengthening and FE modelling. 